to what can be done in the way of accounting for secondary electron maxima of cobalt on the basis of electron waves. Attempts to correlate, in a similar way, the maxima observed with other metals are now being made.

Laboratory of Physics,

University of Wisconsin, Madison, Wisconsin.

\section{Temperatures of Positive Ions in a Uniformly Ionised Gas.}

A GAS through which a current is passing may be considered as a mixture of three gases-neutral molecules, electrons, and positive ions. In regions of relatively small field and space charge, each of these gases will show an approximate Maxwellian distribution of energies among the particles, that is, will be in temperature equilibrium within itself, but each gas will have a different temperature. Even at gas pressures so high as a millimetre of mercury, and in an almost field-free space, the temperature of the positive ions will be very much higher than the temperature of the neutral molecules with which they are continually colliding. The only available source of energy of random motion appears to be the electron gas, which is at a still higher temperature. L. H. Thomas (Proc. Royal Soc., A, 121, 464; 1928) derives formulæ for the interchange of energy between particles interacting according to the inverse square law and uses them to explain the rapidity with which a Maxwellian distribution of velocities is set up within an electron gas. They may also be used to calculate the temperature of the positive ions from the temperature of electrons and the pressure of the gas in a field-free space.

For comparison with the calculations, data of mine on the width of lines emitted from the negative glow of the helium arc will be used (Phys. Rev., 32, 918; 1928). The following assumptions form the basis of the calculations :

1. The positive ions acquire energy solely from the energy of random motion of the electrons.

2 . They lose energy by collision with the molecules of neutral helium at a rate which may be calculated from kinetic theory.

The rate at which the positive ions acquire energy from the electrons is calculated from formulæ $(4.22)$ and $(4 \cdot 23)$ of Thomas's paper, assuming all the electrons to have the most probable velocity and neglecting the velocity of the positive ions. In calculating the loss of energy to the neutral molecules, the latter are taken as stationary and the radius of the ion is taken from the Bohr theory of the helium ion. Equating the rate of gain to the rate of loss gives the calculated temperature. As the pressures were very roughly measured and the ion temperatures are subject to considerable uncertainty, the data do not warrant making a more exact calculation. The comparison is given in Table $I$.

TABLE I.

\begin{tabular}{|c|c|c|c|c|}
\hline $\begin{array}{l}\text { Electron } \\
\text { 'Temp. } \\
\text { (Volts). }\end{array}$ & $\begin{array}{c}\text { Electron } \\
\text { Density } \\
\text { (Electrons/c.c.) }\end{array}$ & $\begin{array}{c}\text { Gas } \\
\text { Pressure } \\
\text { (mm. of } \\
\text { Mercury). }\end{array}$ & $\begin{array}{l}\text { Ion Temp. } \\
\text { Calc. } \\
\text { (Volts). }\end{array}$ & $\begin{array}{l}\text { Ion Temp. } \\
\text { Obs. } \\
\text { (Volts). }\end{array}$ \\
\hline $0 \cdot 66$ & $3.2 \times 10^{12}$ & $1 \cdot 1$ & $0 \cdot 12$ & 0.07 \\
\hline 0.52 & $7 \cdot 5 \times 10^{11}$ & 0.5 & $0 \cdot 11$ & $0 \cdot 10$ \\
\hline $1 \cdot 2$ & $2 \cdot 1 \times 10^{12}$ & 0.4 & $0 \cdot 14$ & $0 \cdot 14$ \\
\hline $0 \cdot 87$ & $3.4 \times 10^{12}$ & $0 \cdot 4$ & 0.22 & $0 \cdot 10$ \\
\hline $0 \cdot 86$ & $1.8 \times 10^{12}$ & $0 \cdot 25$ & $0 \cdot 20$ & $0 \cdot 14$ \\
\hline
\end{tabular}

That the calculated values are consistently high may be due to neglecting the shielding effect of the gas on the interaction of the charged particles or to taking too small a radius for the helium ion. The agreement is within the error of calculation and measurement. It is interesting that even the order of magnitude is correct, as all direct measurements of interaction. between positive ions and gas molecules give values which differ from those calculated from the kinetic theory. Harnwell (Phys. Rev., 31, 634; 1928). for example, found that the loss of energy of alkali ions of high velocities passing through helium was only a few per cent of that expected. Ramsauer and Beeck (Ann. der Physik, 87, 1; 1928) made measurements on the same ions which extended to velocities so low as one volt, and found that the effective radii of interaction were always larger than the predicted radii and increased rapidly as the velocity decreased. The radius of the helium ion is so small compared to the radius of the helium atom that doubling or tripling it would have only a small effect on the calculated temperatures of Table I. Interesting results of the calculation are that the ion temperature should increase with decreasing electron temperature and increase with increasing electron concentration. The range of variation of electron density and temperature in these experiments is too small to test these conclusions.

\section{JANE M. DEwhy}

(National Research Fellow).

Palmer Physical Laboratory,

Princeton University,

Princeton, N.J., April 5.

\section{Selenium and Cathode Rays.}

Is the course of some experiments upon the lightsensitive properties of selenium, evidence has been obtained by me of what appears to be a direct action of cathode rays upon the grey crystalline form of that substance.

The cell was prepared by condensing vapour of heated selenium upon a gold grid. It was placed in a glass tube which could be exhausted and so arranged that a pencil of cathode rays fell upon the crystals after passing through the openings in an earth. connected metal gauze tube which completely surrounded the cell. The cell itself was also connected to earth.

Precautions were taken to absorb all mercury vapour that might otherwise have diffused from the pump into the exhausted vessel and provision was also made for the elimination of moisture.

A simple plan was devised to detect the effect, if any, of the slight luminosity due to fluorescence that appeared when the discharge occurred, and a series of control experiments were made with all conditions similar except that a plain gold grid without selenium was placed within the earthed gauze screen.

The anode was sealed into a side tube behind the cathode and at a distance of about one inch from it.

It was found that, although the selenium cell used was markedly sensitive to light, no appreciable effect whatever was produced by the slight luminosity of the tube due to fluorescence either of the walls or of the glass strip upon which the selenium was deposited.

When the cell was exposed to cathode rays, however, a rapid diminution of resistance occurred which could be widely varied by deviating the rays with a magnet.

The cell exhibited many of the effects observed when light was shone upon it but the lag was less. Its resistance somewhat increased at first, due to the bombardment, so that the "dark current' was reduced. This effeet was not permanent, but 